\title{
Threshold alarm tests of electrical devices for the detection of combustible gases in domestic premises
}

\author{
Marius Darie * , Dănuţ-Nicolae Grecea, and Cosmin-Ioan Colda \\ National Institute for Mine Safety and Protection to Explosion - INSEMEX, Department for Safety of \\ Installations and Explosion-proof Equipment, 32-34 G-ral Vasile Milea, Petrosani, Romania
}

\begin{abstract}
The paper describes a measuring system for testing of the combustible gases detectors used in domestic premises. The general requirements are presented for the electrical equipment used in gas detection. A theoretic analytical model is proposed for measuring the test gas concentration and assessing the influence of air humidity. The requirements considered for designing the measuring system are presented for the experimental setup. The presented assembly structure was tested and the results were presented. Consequently, the measurement uncertainty was determined. It was found that the use of a high precision oxygen analyzer is reliable in the process of calibration testing. It was also found that the variation of relative humidity during the measurement influences the gas concentration measured.
\end{abstract}

\section{Introduction}

The use of flammable gases in domestic premises is a common situation in Europe but not only in Europe [1, 2].

In areas where a methane network has no incidence there are other flammable gases, such as LPGs (Liquefied Petroleum Gas), used in domestic premises.

As consequence of the above mentioned, the flammable gases could not be avoided from domestic premises and the uses of them imply also disadvantages.

The use of flammable substances in domestic premises, together with lack of knowledge related to the explosion hazard, requires that additional precautions are taken in order to reduce the associated risk.

The hazards related to the use of flammable substances are fire, explosions [3] and suffocation. From the list of hazards, explosions are distinguished by the gravity of consequences to the vicinity of the area affected.

In the industrial field, in order to prevent such explosions a set of requirements are mandatory. Thus, monitoring [4-6] the concentration, ventilation, explosion protection and protective systems are practically the employed measures for mitigation of explosion hazards.

\footnotetext{
* Corresponding author: marius.darie@insemex.ro
} 
Equivalent measures are also used in domestic premises. Thus, concentration monitoring, natural ventilation and overpressure release surfaces in case of explosions are employed. In domestic premises, the lack of explosion protection is also covered by the increase of the safety factor for detection threshold in the monitoring process.

For example, the alarm threshold is required to be about $10 \%$ of lower flammable limit. This fraction is chosen and configured by the manufacturer of the gas detector.

Regarding this aspect, the issue which arises is the absolute value of the alarm threshold for flammable gases having small values of lower flammable limit (for example in the case of butane).

\section{Requirements for electrical apparatus for the detection of combustible gases in domestic premises}

The equipment used in the domestic premises, for the purpose of detection of flammable gases should comply with the requirements mentioned in the specific standard [7].

According to the specific standard, the requirements for electrical apparatus for the detection of combustible gases in domestic premises have in view two types of detection equipment, type $\mathrm{A}$ and $\mathrm{B}$. The detection equipment of type $\mathrm{A}$ is able to generate a signal for an action (for example closing the gas valve) and not just generating an acoustic and visual alarm as type B does.

In case of detection apparatus for which the sensors can be replaced, it is required that the new sensors should have the same performances as the previous ones.

The constructional requirements for the detection apparatus are related to: protection against live parts, heating, leakage current and dielectric strength at operating temperature, moisture resistance, overload protection of transformers and associated circuits, abnormal operation, internal conductors, components, power connections and flexible external cables, terminals for external conductors, earthing connections, screws and connections, creepage distances, clearances and separation distances through solid insulation, resistance to heat and fire and resistance to rust.

Regarding the indicators and alarms, the requirements are about the colors of optical alarms and about acoustic alarms. Also, the declared threshold alarm should be set between $3 \%$ and $20 \%$ of LFL (Lower Flammable Limit) of the detected flammable substance. A maximum delay of 2 minutes is permitted for the acoustic alarm. The detection apparatus should generate a fault signal in the event of a faulty sensor.

The marking and instructions are also regulated by the specific standard.

\section{Theoretical model for measuring the protective gas concentration}

A high precision oxygen analyzer - Servoflex MiniMP 5200 [8] was used for the purpose of measuring concentrations of test gas. This analyzer has a precision of $0.01 \% \mathrm{v} / \mathrm{v}$ in normal conditions.

First, a zero calibration was done using nitrogen. Consequently, a calibration using air in normal conditions of pressure, temperature and moisture was completed.

In order to increase the sensitivity of the system five times, in process of calibration with air, the indication of analyzer was set to be around $100 \%$.

For the purpose of high precision calibration, the water concentration in the air (humidity) was measured and computed.

The water concentration in the air could be obtained by using equation 1 . 


$$
\mathrm{C}_{\text {water }}=\frac{e^{\prime} \cdot \mathrm{RH}}{\mathrm{P}}
$$

where: $e_{s}$ is the saturation vapor pressure computed as function of temperature and atmospheric pression $p$, in $\mathrm{Pa}$. It was computed using the ITS-90 formulations for vapor pressure and enhancement factors in the range of 0 to $+100{ }^{\circ} \mathrm{C}$ [9], over water in the pure phase; $\mathrm{RH}$ is relative humidity measured in $\%$ and $\mathrm{c}_{\text {water }}$ is the water concentration in $\% \mathrm{v} / \mathrm{v}$.

The concentration of the air mixture used for calibration of gas analyzer at high value, was obtained using equation 2 .

$$
\mathrm{c}_{\text {max }}=\mathrm{c}_{\text {water }} \cdot k_{\text {water }}+\left(100-\mathrm{c}_{\text {water }}\right) k_{\text {air }}
$$

where $\mathrm{c}_{\max }$ is the computed value of maximum concentration of oxygen measured by analyzer in $\% ; \mathrm{k}_{\mathrm{air}}=0.2094385$ and $\mathrm{k}_{\mathrm{water}}=0.0003$ are paramagnetic offset coefficients [10].

The actual concentration of oxygen in the measured mixture, was obtained using equation 3 .

$$
\mathrm{c}_{\text {O2actual }}=\frac{\left(c_{\max }-c_{\min }\right)\left(i_{O 2 \operatorname{shown}}-i_{\min }\right)}{i_{\max }-i_{\min }}+c_{\min }
$$

where $i_{\min }$ and $i_{\max }$ are analyzer indications at low and high calibration in $\% ; c_{\min }$ and $c_{\max }$ are actual concentrations at low and high calibration in $\%$; $\mathrm{c}_{\mathrm{O} 2 \mathrm{actual}}$ is the actual concentration of $\mathrm{O}_{2}$ of the mixture in $\%$.

The actual concentration of gas in the measured mixture, was obtained using equation 4.

$$
\mathrm{c}_{\text {gas }}=100 \cdot\left[1-\left(\frac{\left(\frac{c_{\text {Ozactual }}}{100}-k_{\text {gas }}\right)}{\left(\frac{c_{\text {water }}}{100} \cdot k_{\text {water }}+k_{\text {air }} \cdot\left(1-\frac{c_{\text {water }}}{100}\right)-k_{\text {gas }}\right)}\right)\right]
$$

where $\mathrm{c}_{\mathrm{gas}}$ is the actual concentration of gas in the mixture in $\%$ and $\mathrm{k}_{\mathrm{gas}}$ is the paramagnetic offset coefficient for the measured test gas [10].

\section{Requirements for the integrated test system intended for the detection of flammable gases}

Some specific requirements of the integrated test system are: a graphical interface for the integrated test system intended for the detection of flammable gases (the sampling rate should be at least $1 \mathrm{~Hz}$ ); the precision should be $100 \mathrm{vpm}(\mathrm{ppm})$ for concentration measurement and $0.1 \mathrm{hPa}$ (mbar) for pressure measurement; ability to record the measured and computed values; gas mixture pump, simple / customizable structure and transportability.

In figure 1 is presented the bloc diagram of the integrated system for the gas detector threshold alarm tests. In this diagram the gas mixture pump is part of the analyzer.

Grey arrows indicate the path of gas mixture, and blue arrows show the information path between blocks.

Between the monitoring system and oxygen analyzer, is an online connection. Between the monitoring system, pressure sensor, and thermo-hygrometer is an offline connection. The reading rate from analyzer is $1 \mathrm{~Hz}$. The reading of pressure, temperature, and humidity are made once in a measurement session (by the operator). This information is used for establishing the ambient data and conditions for performing the tests.

By using this testing system, the device under test (DUT) is exposed to a gas mixture in order to test the alarm threshold (DUT represents the apparatus for detection of flammable 
gases). The oxygen analyzer contains the gas mixture pump. This pump, together with the fan installed in the test chamber, help the mixing process. The gas detector under test is also placed in the testing chamber. The test chamber has facilities for gas exchange and electricity supply for the DUT and fan.

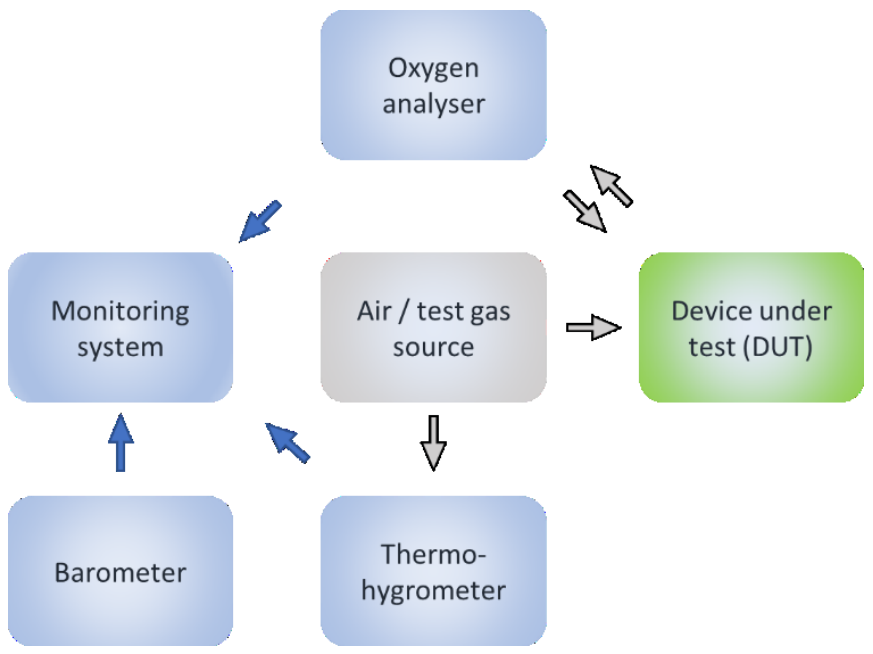

Fig. 1. Integrated system for gas detector threshold alarm tests - block diagram

The sampling point is located near the DUT in order to measure the gas mixture which flow near to it. The path of this cycle was prolonged in order to ensure the release of heat generated by the DUT.

Between fan and DUT, in the test chamber, was placed a permeable membrane. This membrane was provided in order to prevent turbulences and flowing of test gas at high speed near the DUT (which can be induced by the fan in the mixing process).

The inlet of the test chamber is located in the rear part of it. Also, at this point is placed the inlet for the test gas. The test gas is injected in the system using a piston device.

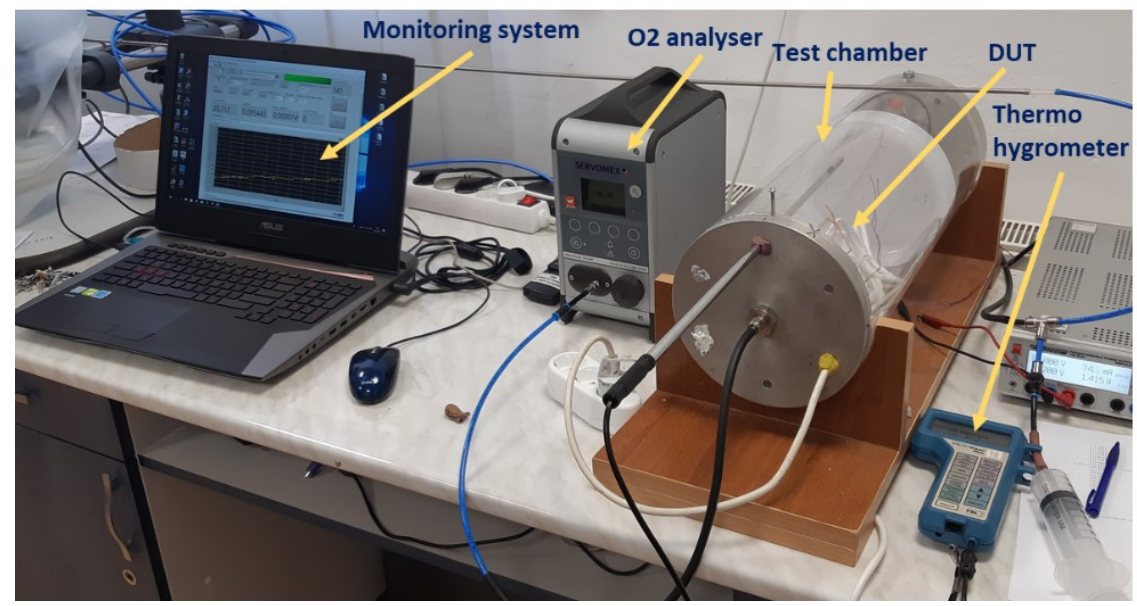

Fig. 2. Integrated system for gas detector threshold alarm tests

The operating procedure starts with the calibration step. At this stage the oxygen analyzer of the system is calibrated at low value using nitrogen. 
At the calibration stage for high values of oxygen concentrations, air is supplied in the system. The humidity of the inlet air is measured. The water concentration and oxygen concentration are computed.

At this stage the indication of the analyzer is set up to around $100 \%$. By doing this, the sensitivity of the analyzer is increased five times.

The performances of the presented system are: sensitivity of about $100 \mathrm{vpm}(0.01 \% \mathrm{v} / \mathrm{v})$ with an uncertainty around $0.008 \% \mathrm{v} / \mathrm{v}$; sampling rate of the reading and recording: $1 \mathrm{~Hz}$.

The fields of recorded data are: date/time; atmospheric pressure [mbar]; temperature $\left[{ }^{\circ} \mathrm{C}\right]$; $\mathrm{RH}[\%]$; gas temperature $\left[{ }^{\circ} \mathrm{C}\right]$; gas $\mathrm{RH}[\%]$; gas name; gas paramagnetic offset $[\%]$; test time [s]; concentration of $\mathrm{O}_{2}[\%]$; water concentration [\%]; gas concentration [\%]; operator comment.

In the process of testing, the relative humidity of the inlet air used for gas mixture preparation was varying around $38 \%$, the atmospheric pressure was around 939 mbar, and temperature approximative $20^{\circ} \mathrm{C}$.

The theoretical model implemented in the monitoring system has been designed having in view that the relative humidity of the air in the process of measuring is not varying.

The effect of relative humidity variation on the computed gas concentration for the same set of parameters values as it is mentioned in the Table 1 has been assessed by changing the value of relative humidity to $60 \%$. The obtained test gas concentration was $0.14249 \%$ which corresponds to a variation of $0.3 \mathrm{vpm}$.

Table 1. Uncertainty budget

\begin{tabular}{|c|c|c|c|c|c|c|}
\hline Quantity & Value & $\begin{array}{l}\text { Standard } \\
\text { Uncertainty }\end{array}$ & $\begin{array}{l}\text { Degrees of } \\
\text { Freedom }\end{array}$ & $\begin{array}{l}\text { Sensitivity } \\
\text { Coefficient }\end{array}$ & $\begin{array}{c}\text { Uncertainty } \\
\text { Contribution }\end{array}$ & Index \\
\hline $\mathrm{RH}$ & $38.00 \%$ & $2.20 \%$ & 50 & $-1.6 \cdot 10^{-6}$ & $-3.6 \cdot 10^{-6} \%$ & $0.0 \%$ \\
\hline $\mathrm{t}_{\mathrm{amb}}$ & $19.900 \operatorname{grad} \mathrm{C}$ & $0.500 \operatorname{grad} \mathrm{C}$ & 50 & $-3.9 \cdot 10^{-6}$ & $-2.0 \cdot 10^{-6} \%$ & $0.0 \%$ \\
\hline $\mathrm{p}_{\text {atm }}$ & $939.000 \mathrm{mbar}$ & 0.190 mbar & 50 & $66 \cdot 10^{-9}$ & $12 \cdot 10^{-9} \%$ & $0.0 \%$ \\
\hline $\mathrm{c}_{\text {O2shown }}$ & $99.65000 \%$ & $2.89 \cdot 10^{-3} \%$ & $\infty$ & -0.95 & $-2.7 \cdot 10^{-3} \%$ & $50.1 \%$ \\
\hline $\mathrm{c}_{\text {O2actual }}$ & $20.7392 \%$ & $0.0115 \%$ & 78 & & & \\
\hline $\mathrm{c}_{\max }$ & $20.7705 \%$ & $0.0115 \%$ & 77 & & & \\
\hline $\mathrm{c}_{\min }$ & $1.000 \cdot 10^{-3} \%$ & $289 \cdot 10^{-6} \%$ & $\infty$ & $-6.9 \cdot 10^{-3}$ & $-2.0 \cdot 10^{-6} \%$ & $0.0 \%$ \\
\hline $\mathrm{i}_{\max }$ & $99.80000 \%$ & $2.89 \cdot 10^{-3} \%$ & $\infty$ & 0.95 & $2.7 \cdot 10^{-3} \%$ & $49.9 \%$ \\
\hline $\mathrm{i}_{\min }$ & $-0.01000 \%$ & $2.89 \cdot 10^{-3} \%$ & $\infty$ & $1.4 \cdot 10^{-3}$ & $4.1 \cdot 10^{-6} \%$ & $0.0 \%$ \\
\hline $\mathrm{k}_{\text {water }}$ & $300.0 \cdot 10^{-6}$ & & & & & \\
\hline $\mathrm{k}_{\mathrm{air}}$ & 0.2094385 & & & & & \\
\hline $\mathrm{k}_{\mathrm{gas}}$ & -0.0113 & & & & & \\
\hline $\mathrm{c}_{\text {gas }}$ & $0.14252 \%$ & $3.88 \cdot 10^{-3} \%$ & $\infty$ & & & \\
\hline
\end{tabular}

In Table 1 the signification of parameters used are: RH - relative humidity (measured); $\mathrm{t}_{\mathrm{amb}}$ - ambient temperature (measured); $\mathrm{p}_{\mathrm{atm}}$ - atmospheric pressure (measured); $\mathrm{c}_{\mathrm{O} 2 \mathrm{shown}}$ indication of oxygen analyzer (read through connection with oxygen analyzer); $\mathrm{c}_{\mathrm{O} \text { actual }}$ real oxygen concentration (computed); $\mathrm{c}_{\max }$ - real oxygen concentration in the air (computed); $\mathrm{c}_{\min }$ - established from the datasheet of gas (nitrogen) used for zero calibration; $\mathrm{i}_{\max }$ - indication of the oxygen analyzer at calibration time (high); $\mathrm{i}_{\min }$ indication of the oxygen analyzer at calibration time (zero calibration); $\mathrm{k}_{\mathrm{water}}, \mathrm{k}_{\mathrm{air}}, \mathrm{k}_{\mathrm{gas}}-$ paramagnetic offset of water, air or gas; $c_{\text {gas }}$ - computed gas concentration. 
The measurement uncertainty has been computed using GUM Workbench 1.3.6.150 software.

In figure 3 is presented a screenshot of the interface implemented in GUM Workbench 1.3.6.150 software for the model equation regarding the measurement uncertainty. In this interface were implemented the equations (1) to (4) together with those mentioned in [9].

The analysis of the uncertainty budget underlined the importance of the value shown by the oxygen analyzer in the measurement process and also the value shown at calibration moment (for high value).

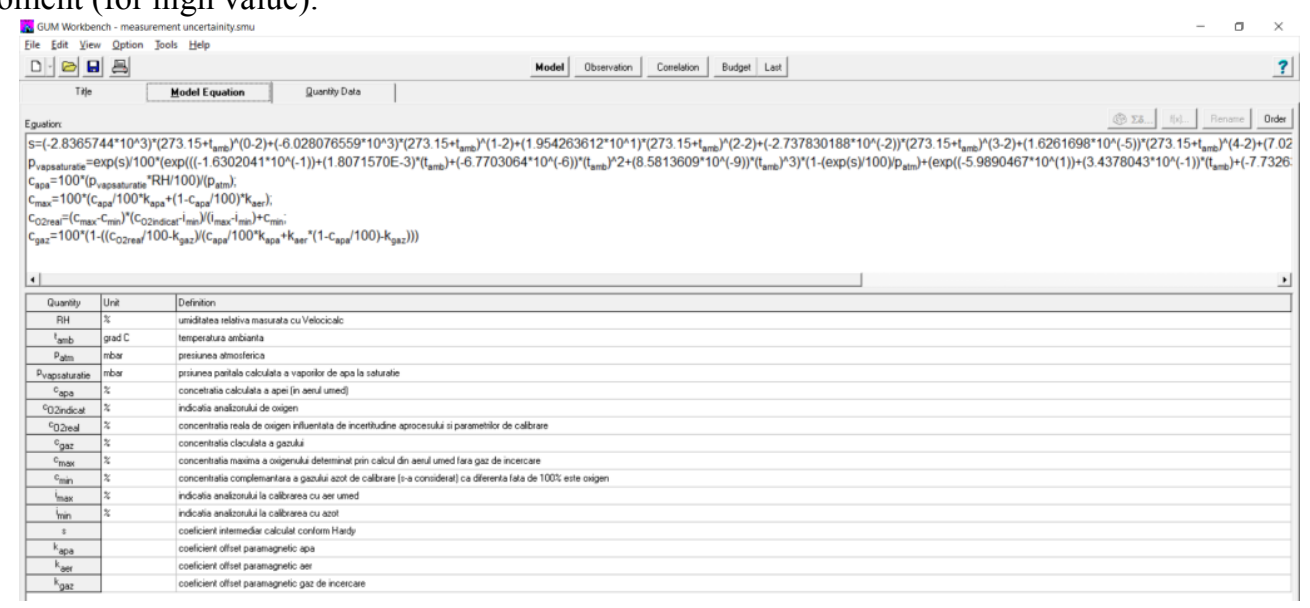

Fig. 3. Screenshot of the interface from GUM Workbench 1.3.6.150 software for the model equation

\section{Conclusion}

In the paper is exposed a practical way for using a high precision oxygen analyzer as a main part in a system designed for performing the threshold alarm tests of apparatus intended for detection of flammable gases in the domestic premises.

The increase of sensitivity of the oxygen analyzer could be done by changing the indication reference of the analyzer in the process of calibration for high values from $20.95 \%$ to $100 \%$.

The theoretical model implemented in the monitoring system together with the calibration of the analyzer has permitted to achieve finesse of measurement of $100 \mathrm{vpm}$ or $0.01 \% \mathrm{v} / \mathrm{v}$.

It was found that the relative humidity variation does not have a significative influence over the computed gas concentration. The performed simulation outputted a variation under $0.5 \mathrm{vpm}$ for the computed test gas concentration.

The analysis of the uncertainty budget revealed that the value shown by oxygen analyzer in the measurement process and the value shown during calibration at high values play an important role in the uncertainty budget.

Future efforts will be focused on the reduction of noise that occurs during the measurement.

\section{References}

1. C. Dura, O. Dobre Baron, Best Practices in Romanian CSR: Petrom OMV's Strategy, Quality, Acces to Success Journal,16 (149), 62-67, ISSN 1582-2559 (2015) 
2. J. Grabara, C. Dura, I. Drigă, Corporate Social Responsibility Awareness in Romania and Poland: A Comparative Analysis, Journal of Scientific Papers Economics \& Sociology Vol. 9 (4), 344350 (2016)

3. M. Prodan, E. Ghicioi, C. Lupu, I. Nălboc, A. Szollosi-Mota, (2016), Flammability characterisation of a petroleum derivative for increasing the safety of personnel and environmental protection, International Multidisciplinary Scientific GeoConference: SGEM 2016: Surveying Geology \& mining Ecology Management, vol. 4, p. 119-125 (2016)

4. A. Mahalingam, R. T. Naayagi, N. E. Mastorakis, Design and Implementation of an Economic Gas Leakage Detector, Recent Researches in Applications of Electrical and Computer Engineering, 20-24 (2012)

5. P. Bansal, R. Thareja, Recent advances and techniques in the Hazardous gases detection, Handbook of Ecomaterials (Springer, 2018)

6. A. Schmidt, Technical Thermodynamics for Engineers, (Springer International Publishing, Springer Nature Switzerland AG, 2019)

7. EN 50194-1 (2009)

8. Servoflex MiniMP 5200. Available on https://www.servomex.com/gas-analyzers/productranges/servoflex/servoflex-minimp

9. B. Hardy, ITS-90 Formulations for vapor pressure, frost point temperature, dewpoint temperature, and enhancement factors in the range -100 to $+100 \mathrm{C}$ (Thunder Scientific Corporation, Albuquerque, NM, US, 1998)

10. Xendos 2200 SERVOMEX Operator Manual Ref: 02210/001A/4 Order as part no. 02210/001A available on https://www.servomex.com/downloadable/download/sample/sample_id/295/ 